\title{
OCORRÊNCIA, ABUNDÂNCIA E DIVERSIDADE DA ICTIOFAUNA NA PESCA DO CAMARÃO SETE-BARBAS, NA REGIÃO DE PENHA, SC
}

\author{
BAIL, G. C. ${ }^{1}$ \& J.O. BRANCO ${ }^{2}$ \\ Centro de Ciências Tecnológicas da Terra e do Mar, CTTMar - UNIVALI, Caixa Postal \\ 360, CEP 88302-202, SC. E-mail: 1gilabail@bol.com.br, ${ }^{2}$ branco@cttmar.univali.br
}

RESUMO

\begin{abstract}
Nas pescarias de arrasto do camarão sete-barbas pela frota artesanal, uma parcela significativa de fauna capturada é constituída por peixes, os quais, geralmente, são devolvidos mortos ao mar, por não apresentarem tamanho ou valor comercial. As amostragens da ictiofauna foram efetuadas mensalmente a bordo de barcos da frota artesanal que operam na região de Penha, SC, Brasil, durante o período de Agosto/2001 a Julho/2002. Foram amostrados 6719 peixes, pertencentes a 22 famílias, distribuídas em 37 espécies. A ictiofauna apresentou oscilações sazonais em número de exemplares e CPUE. Os índices de riqueza de espécies e diversidade apresentaram padrões semelhantes de variação e os valores de equitabilidade revelaram uma distribuição uniforme das espécies nas áreas de coleta.
\end{abstract}

Palavras chaves: ictiofauna, diversidade, Penha, Brasil

\section{OCCURRENCE, ABUNDANCE AND DIVERSITY OF ICHTHYOFAUNA IN SEA- BOB-SHRIMP FISHERY IN THE AREA OF PENHA, SC}

\begin{abstract}
A significant portion of the captured fauna in sea-bob-shrimp fisheries is composed by fish, which are non-commercial species or non-commercial size, thus being generally returned (dead) back to sea. Our samples were obtained monthly on board of artisanal fleet vessels that operated along the area of Penha, SC, Brazil, from August/2001 to July/2002. A total of 6719 fishes were captured, distributed in 22 families where 37 fish species were identified. The ichthyofauna presented seasonal oscillations in number of specimens, as well as, CPUE. Richness and diversity indexes resulted in similar patterns of variation and equitability values revealed an uniform distribution of species in sampled areas.
\end{abstract}

Key words: ichthyofauna, diversity, Penha, Brazil

\section{INTRODUÇÃO}

O produto da pesca do camarão setebarbas é caracterizado por uma grande multiplicidade faunística, a qual é composta de crustáceos, moluscos, peixes, equinodermos e cnidários (Rodrigues et al., 1985; Branco, 1999). A participação dessa fauna nos arrastos é freqüentemente elevada, superando a quantidade de camarões em condições de comercialização (Coelho et al., 1986).

No Brasil, em especial no litoral catarinense, a análise da rejeição da fauna acompanhante é ainda incipiente; essa deficiência é marcante na pesca artesanal do camarão sete-barbas, onde uma elevada quantidade de peixe é devolvida morta ao mar por não possuir valor econômico considerável 
(Branco, 1999). Para Ruffino \& Castello (1992/ 93) a presença da ictiofauna na pesca do camarão é fato conhecido e discutido, sendo considerado recurso subutilizado e freqüentemente descartado.

Grande parte da ictiofauna capturada é composta por peixes juvenis, o que pode vir a ser inadequado para a manutenção dos estoques em níveis aceitáveis. Dessa forma, o conhecimento da ictiofauna é de fundamental importância, visto que a pesca de arrasto é predatória e freqüentemente realizada em criadouros de diversas espécies de peixes juvenis (Coelho et al., 1986; Ruffino \& Castello, 1992/93). Não se sabe até que ponto a grande mortalidade dessa fauna afetará o equilíbrio ecológico das áreas de pesca (Rodrigues et al., 1985). Este trabalho tem por objetivo caracterizar a composição e abundância da ictiofauna acompanhante da pesca artesanal do camarão sete-barbas na região de Penha, SC. A identificação da fauna que é fortemente afetada pela pesca é de interesse primordial.

\section{MATERIAL E MÉTODOS}

As amostragens foram efetuadas mensalmente, a bordo dos barcos da frota artesanal, durante o período de agosto/2001 a julho/2002, entre a Praia de Armação e o distrito da Armação do Itapocoroy, no município de

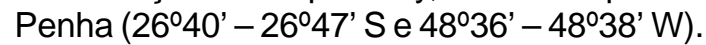
Em cada embarque foram efetuados arrastos em três áreas distintas (Fig. 1), com duração média de 30 minutos. Os exemplares foram capturados com tangones providos de duas redes-de-arrasto com portas, malha de $3,0 \mathrm{~cm}$ na manga e corpo e $2,0 \mathrm{~cm}$ no ensacador, sendo tracionadas com velocidade média de dois nós (Branco, 1999).

O produto de cada arrasto foi pesado, acondicionado em sacos plásticos, etiquetado, mantido em caixa de isopor com gelo e posteriormente transportado para o laboratório.

Os exemplares integrantes da ictiofauna foram identificados de acordo com Figueiredo
\& Menezes (1978), Figueiredo (1980) e Menezes \& Figueiredo (1980), sendo registrado a espécie e sua contribuição em peso e em número de indivíduos. Foi calculada a captura por unidade de esforço (CPUE em Kg/hora de arrasto), mensalmente para cada área de amostragem. De acordo com a ocorrência nas coletas, as espécies foram classificadas em três categorias: regular ( 9 a 12 meses); sazonal (6 a 8 meses)e ocasional (1 a 5 meses) (Ansari et al., 1995).

Para estimar a diversidade foram escolhidos três índices considerados os mais informativos e calculados mensalmente para cada área de amostragem, conforme Ludwig \& Reynolds (1988):

- Índice de riqueza específica de Margalef (D)

$$
\mathrm{D}=(\mathrm{S}-1) / \ln (\mathrm{n})
$$

. Índice de diversidade de Shannon (H')

$$
\left.H^{\prime}=\text { - å [ (ni/n) * } \ln (n i)\right]
$$

. Índice de Equitabilidade de Pielou (J')

$$
J^{\prime}=H^{\prime} / \ln (S)
$$

onde S é o número de espécies, n é o número total de indivíduos e ni é o número de indivíduos da espécie i em cada arrasto.

Após verificada anormalidade dos dados de CPUE em $\mathrm{kg}$ e número de exemplares, foi aplicada a análise de variância (ANOVA) conforme Sokal \& Rohlf (1969), com auxílio do software Instat, a fim de verificar se ocorrem variações entre as áreas de amostragens, ao longo do período de estudo.

\section{RESULTADOS}

Foram amostrados 6719 exemplares com uma biomassa de $101,4 \mathrm{Kg}$, pertencentes à 22 famílias, distribuídos em 37 espécies 


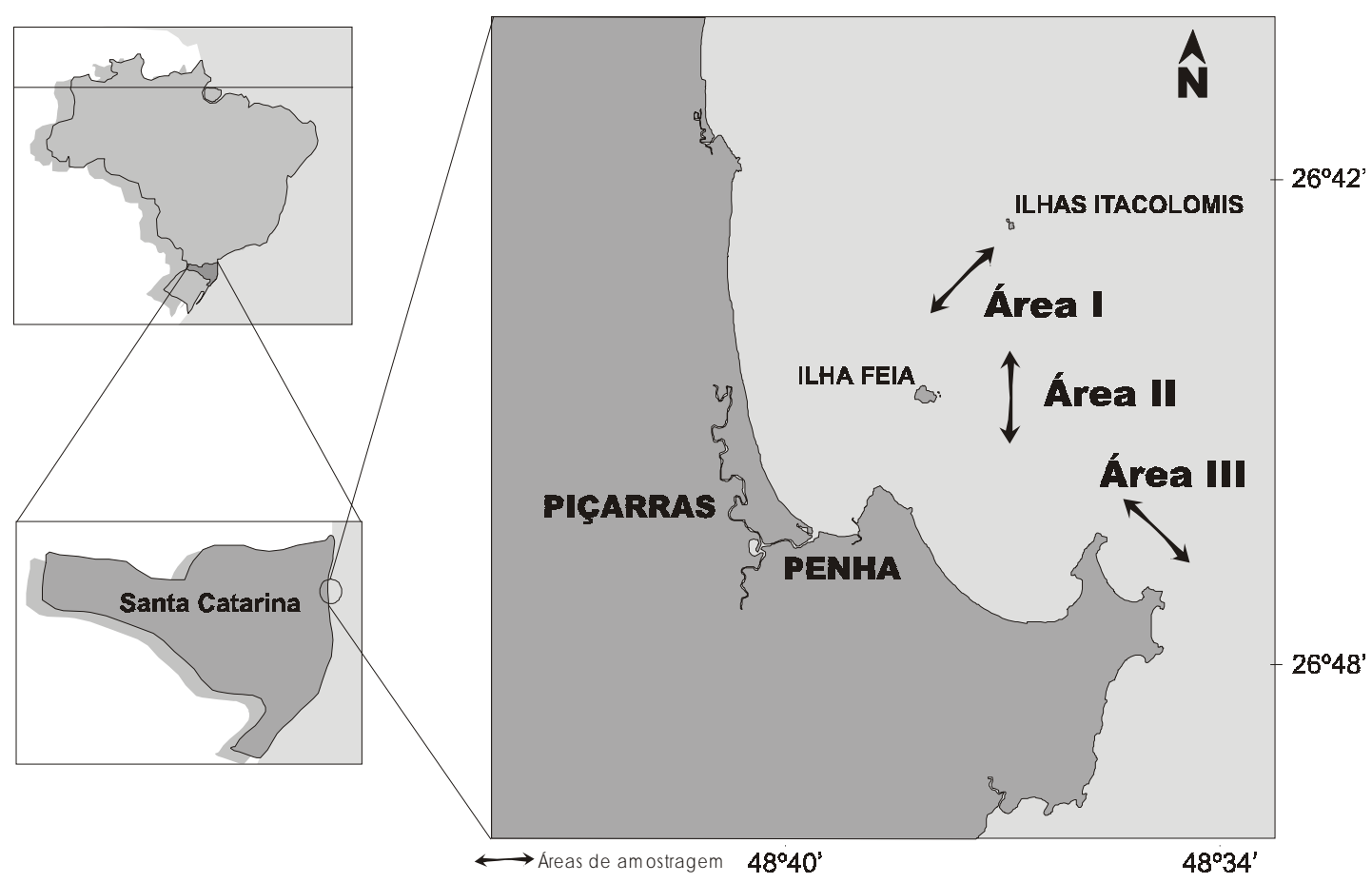

Figura 1 - Mapa da área de estudo indicando as áreas de amostragens.

(Tabela 1), destas, 17 espécies foram comuns às três áreas de amostragens.

A área de maior diversidade de espécies foi a II, com 32, seguida das áreas III com 26 e I com 24 espécies (Tabela 1). Em relação ao número total de exemplares por área, a III destacou-se com 3090 indivíduos, seguido da I (2032) e Il com 1597 (Tabela 1).

\section{Contribuição das famílias}

Das 22 famílias registradas, quatro representaram mais de $91,00 \%$ do total de exemplares capturados (Fig. 2a). A família Sciaenidae contribuiu com $82,14 \%$ do número total de peixes, seguidos da Carangidae $(4,11 \%)$, Clupeidae $(3,78 \%)$ e Engraulidae $(1,29 \%)$; enquanto que as 18 famílias restantes de menor abundância, participaram em conjunto com 8,68\% do número total de exemplares (Fig. 2a).
Em relação ao peso, essas quatro famílias contribuíram com $85,40 \%$ da ictiofauna (Fig. 2b). A família Sciaenidae manteve o domínio com $82,15 \%$ da biomassa, seguida dos Clupeidae (1,43\%), Carangidae (1,06\%) e Engraulidae (0,76\%) (Fig. 2b). As demais famílias representaram $14,60 \%$ da ictiofauna capturada.

\section{Ocorrência das espécies}

A figura 3 representa as ocorrências das espécies, onde mais de $75,00 \%$ foram consideradas ocasionais para as três áreas de coleta. As espécies regulares não ultrapassaram $15,38 \%$ na área III, $12,50 \%$ na I e $6,25 \%$ na II (Fig. 3). Para a área I não foram registradas espécies sazonais, enquanto que na II, estas representaram $18,75 \%$ e na III apenas $7,69 \%$ (Fig. 3). 
BAIL \& BRANCO: Abundância e diversidade da ictiofauna.

Tabela 1 - Relação das espécies de peixes e suas respectivas freqüências no período de coleta, na região de Penha, SC, durante Agosto/2001 a Julho/2002. A ocorrência das espécies é representada por > = regular; + = sazonal; <= ocasional.

\begin{tabular}{|c|c|c|c|c|c|c|c|}
\hline \multirow{2}{*}{$\begin{array}{l}\text { Família/Espécie } \\
\text { CHONDRICHTHYES } \\
\text { Narcinidae }\end{array}$} & Área I & Ocor. & Área II & Ocor. & Área III & Ocor. & Total \\
\hline & & & & & & & \\
\hline $\begin{array}{l}\text { Narcine brasiliensis (Olfwea, 1831) } \\
\text { OSTEICHTHYES } \\
\text { Ophichtidae }\end{array}$ & 2 & $<$ & 6 & $<$ & 2 & $<$ & 10 \\
\hline $\begin{array}{l}\text { Ophichthus gomesii (Castelnau, 1855) } \\
\text { Rhinobatidae }\end{array}$ & 3 & $<$ & 4 & $<$ & & & 7 \\
\hline $\begin{array}{l}\text { Rhinobatos percellens (Walbaum, 1792) } \\
\text { Clupeidae }\end{array}$ & & & 2 & $<$ & & & 2 \\
\hline Opisthonema oglinum (Lesueur, 1818) & & & 28 & $<$ & & & 28 \\
\hline Pellona harroweri (Fowler, 1917) & 7 & $<$ & 28 & $<$ & 48 & $<$ & 83 \\
\hline Harengula clupeola (Cuvier, 1829) & 8 & $<$ & 31 & $<$ & 96 & $<$ & 135 \\
\hline Chirocentrodus brakerianus (Poey, 1867) & & & 4 & $<$ & & & 4 \\
\hline $\begin{array}{l}\text { Sardinella brasiliensis (Steindacher, 1879) } \\
\text { Engraulidae }\end{array}$ & & & 4 & $<$ & & & 4 \\
\hline Cetengraulis edentulus (Cuvier, 1829) & 4 & $<$ & 2 & $<$ & & & 6 \\
\hline Anchoa spinifera (Valenciennes, 1848) & & & & & 10 & $<$ & 10 \\
\hline $\begin{array}{l}\text { Lycengraulis grossidens Agassiz, } 1829 \\
\text { Ariidae }\end{array}$ & 3 & $<$ & 26 & $<$ & 42 & $<$ & 71 \\
\hline $\begin{array}{l}\text { Netuma barba (Lacépedède, 1803) } \\
\text { Gadidae }\end{array}$ & 2 & $<$ & 2 & $<$ & & & 4 \\
\hline $\begin{array}{l}\text { Urophycis brasiliensis (Kaup, 1858) } \\
\text { Batrachoididae }\end{array}$ & 32 & $<$ & 20 & $<$ & 2 & $<$ & 54 \\
\hline $\begin{array}{l}\text { Porichthys porosissimus (Valenciennes, 1837) } \\
\text { Triglidae }\end{array}$ & 6 & $<$ & 4 & $<$ & 10 & $<$ & 20 \\
\hline $\begin{array}{l}\text { Prionotus punctatus (Bloch, 1797) } \\
\text { Carangidae }\end{array}$ & & & 2 & $<$ & 2 & $<$ & 4 \\
\hline Chloroscombrus crysurus (Linnaeus, 1766) & 3 & $<$ & 2 & $<$ & 5 & $<$ & 10 \\
\hline Selene setapinnis (Mitchill, 1815) & 23 & $<$ & 78 & + & 104 & + & 205 \\
\hline $\begin{array}{l}\text { Selene vomer (Linnaeus, 1758) } \\
\text { Gerreidae }\end{array}$ & 6 & $<$ & 29 & + & 26 & $<$ & 61 \\
\hline $\begin{array}{l}\text { Diapterus rhombeus (Cuvier, 1829) } \\
\text { Haemulidae }\end{array}$ & & & & & 2 & $<$ & 2 \\
\hline Pomadasys corvinaeformis (Steindachner, 1868) & 2 & $<$ & 4 & $<$ & & & 6 \\
\hline $\begin{array}{l}\text { Orthopristes ruber (Cuvier, 1830) } \\
\text { Sciaenidae }\end{array}$ & 2 & $<$ & & & 2 & $<$ & 4 \\
\hline Larimus breviceps (Cuvier, 1830) & & & 30 & $<$ & 27 & $<$ & 57 \\
\hline Cynoscion leiarchus (Cuvier, 1830). & & & 1 & $<$ & & & 1 \\
\hline Isopisthus parvipinnis (Cuvier, 1830) & 574 & $>$ & 175 & + & 284 & $>$ & 1033 \\
\hline Paralonchurus brasiliensis (Steindachner, 1875) & 644 & $>$ & 407 & $>$ & 745 & $>$ & 1796 \\
\hline Stellifer spp. ${ }^{*}$ & 635 & $>$ & 555 & $>$ & 1414 & $>$ & 2604 \\
\hline Micropogonias furnieri (Desmarest, 1823) & & & 9 & $<$ & 13 & $<$ & 22 \\
\hline $\begin{array}{l}\text { Menticirrhus americanus (Linnaeus, 1758) } \\
\text { Pomacanthidae }\end{array}$ & 1 & $<$ & 2 & $<$ & 3 & $<$ & 6 \\
\hline Peprilus paru (Linnaeus, 1758) & 24 & $<$ & 20 & + & 13 & $<$ & 57 \\
\hline
\end{tabular}


Tabela 1 - Continuação.

\begin{tabular}{|c|c|c|c|c|c|c|c|}
\hline \multirow{2}{*}{\multicolumn{8}{|c|}{ Área I Ocor. Área II Ocor. Área III Ocor. Total }} \\
\hline & & & & & & & \\
\hline $\begin{array}{l}\text { Trichiurus lepturus (Linnaeus, 1758) } \\
\text { Paralichthvidae }\end{array}$ & 31 & $<$ & 69 & + & 107 & + & 207 \\
\hline $\begin{array}{l}\text { Etropus crossotus (Jordan \& Gilbert, 1881) } \\
\text { Achiridae }\end{array}$ & & & & & 3 & $<$ & 3 \\
\hline $\begin{array}{l}\text { Achirus lineatus (Linnaeus, 1758) } \\
\text { Cynoglossidae }\end{array}$ & 2 & $<$ & & & & & 2 \\
\hline $\begin{array}{l}\text { Symphurus tesselatus (Linnaeus, 1766) } \\
\text { Balistidae }\end{array}$ & 7 & $<$ & 19 & + & 43 & $>$ & 69 \\
\hline $\begin{array}{l}\text { Balistes vetula (Linnaeus, 1758) } \\
\text { Monocanthidae }\end{array}$ & & & 1 & $<$ & 2 & $<$ & 3 \\
\hline $\begin{array}{l}\text { Stephanolepis hispidus (Linnaeus, 1766) } \\
\text { Tetraodontidae }\end{array}$ & & & 4 & $<$ & 50 & $<$ & 54 \\
\hline $\begin{array}{l}\text { Lagocephalus laevigatus (Linnaeus, 1766) } \\
\text { Diodontidae }\end{array}$ & 9 & $<$ & 27 & $<$ & 35 & + & 71 \\
\hline Cyclichthys spinosus (Linnaeus, 1758) & 2 & $<$ & 2 & $<$ & & & 4 \\
\hline total & 2032 & & 1597 & & 3090 & & 6719 \\
\hline
\end{tabular}

* o gênero Stellifer compreende as espécies: S.brasiliensis, S. rastrifer e S. stellifer
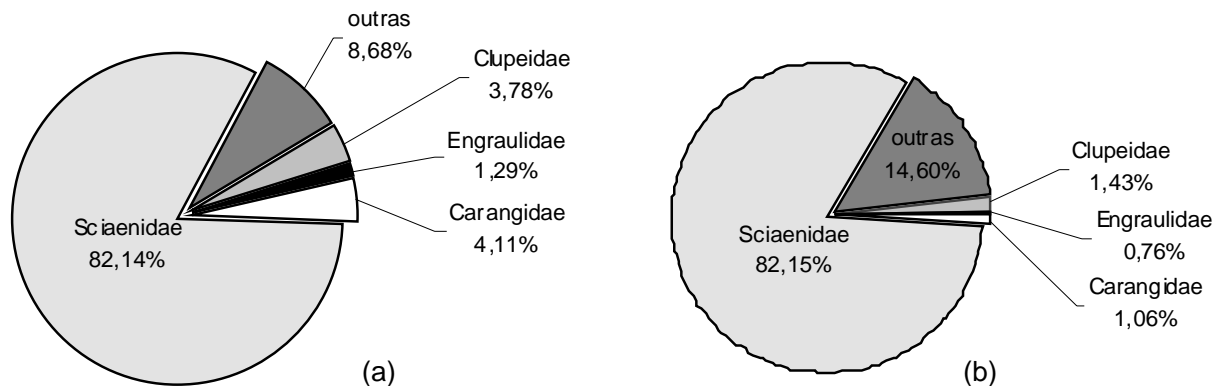

Figura 2 - Contribuição em número (a) e biomassa (b), das principais famílias da ictiofauna acompanhante na pesca artesanal do camarão sete-barbas.

\section{Flutuações espaço-temporais da ictiofauna}

Em geral, as flutuações no número de exemplares capturados nas amostragens tende a acompanhar as variações da CPUE (Fig. 4). $\mathrm{Na}$ área I, as maiores abundâncias de peixes e taxas de capturas ocorreram em dezembro e abril, e as menores, em outubro, fevereiro e junho (Fig. 4a). Para a área II, as maiores capturas foram registradas em abril e junho e as menores em setembro e julho (Fig. 4b). $\mathrm{Na}$ área III, as maiores abundâncias de peixes e taxas de capturas ocorreram em dezembro, janeiro e abril, enquanto as menores, nos meses de inverno e outubro (Fig. 4c). A ANOVA $\left(F_{2-23}=3,585 ; p=0,039\right)$ indica que ocorreram diferenças significativas entre as áreas de coletas e o número de exemplares. As CPUE não apresentaram diferenças significativas entre áreas de amostragens $\left(F_{2-23}=1,168 ; p=0,323\right)$. Analisando a três áreas de coleta em conjunto, verifica-se que a ictiofauna acompanhante apresentou variações mensais no número de exemplares e na CPUE, onde foram registrados 


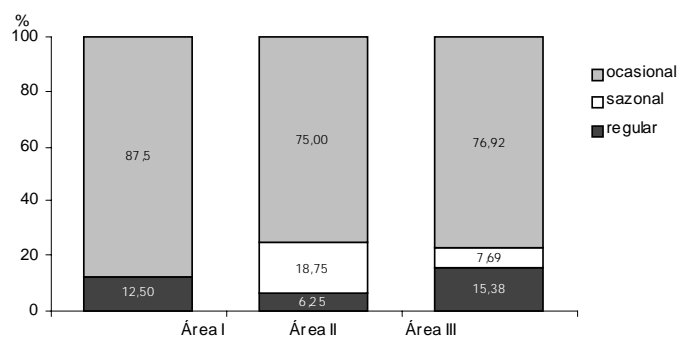

Figura 3 - Ocorrência (\%) das espécies de acordo com suas categorias (regular, sazonal e ocasional), nas três áreas de coleta.

picos de capturas no final da primavera e início do outono (Fig. 4d).

Riqueza, Diversidade e Equitabilidade de espécies

O índice de riqueza de Margalef (D) apresentou flutuações sazonais ao longo do estudo, onde na área I, a menor riqueza de espécies foi registrada no mês de agosto $(0,451)$ e a maior em julho $(1,584)$ (Fig. 5a). Na área II, observou-se a menor riqueza em junho (1,316), e maior em maio (2,511) (Fig. 5a). Para a área III, a menor riqueza foi registrada em setembro $(0,841)$, e a maior em março $(1,686)$. A aplicação da ANOVA $\left(F_{2-33}=15,002 ; p=0,0001\right)$ indicou diferença significativa entre a riqueza de espécies e as áreas de coleta, constatandose que a área I, por apresentar as menores riquezas mensais, se destacou das demais.

$\mathrm{O}$ índice de diversidade de Shannon ( $\left.\mathrm{H}^{\prime}\right)$ apresentou flutuações moderadas e diferentes padrões de oscilações para as três áreas (Fig. 4b). Na área I, a menor diversidade ocorreu em setembro $(0,395)$ e a maior em novembro $(1,394)$ (Fig. 5b). Na área Il, a menor diversidade ocorreu em outubro $(0,788)$ e a maior em março $(2,164)$ (Fig. 5b). Para a área III, o mês de menor diversidade foi setembro $(0,549)$ e julho o de maior (1,690) (Fig. 5b). Ocorreram diferenças significativas ao longo do ano na diversidade das áreas de coleta $\left(F_{2-33}=6,868 ; p=0,003\right)$. $\mathrm{O}$ contraste das médias indicou que a área I
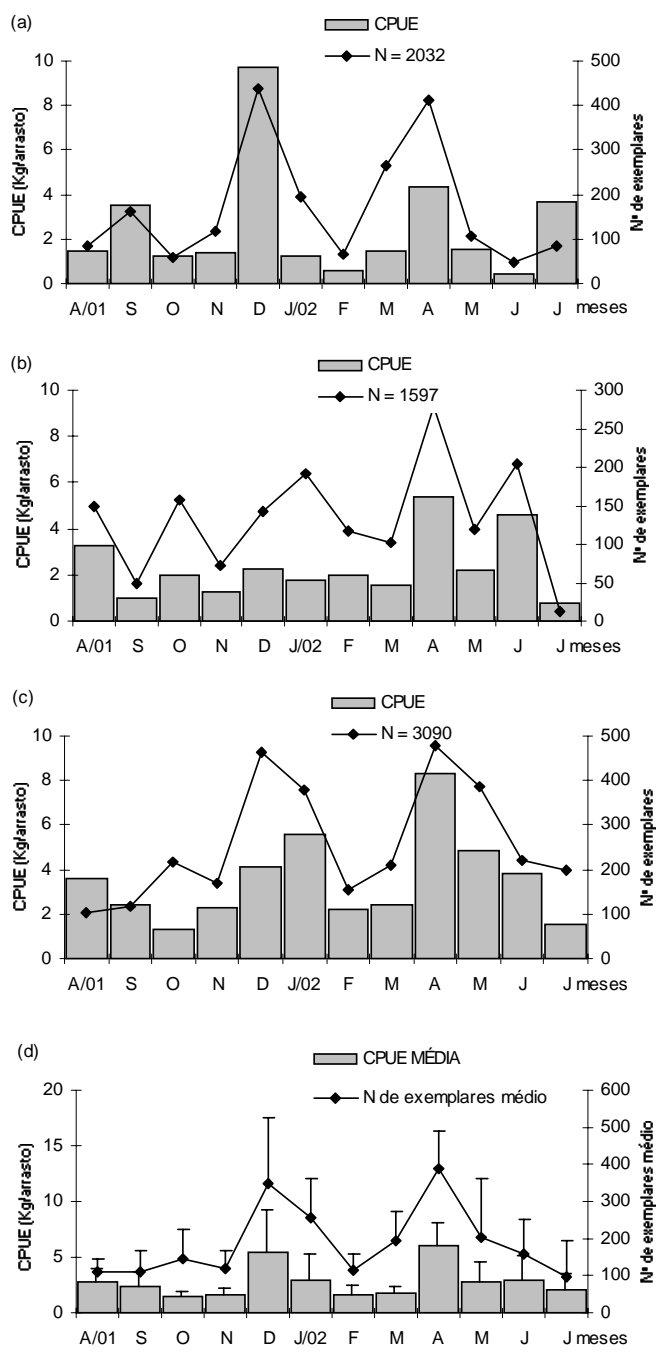

Figura 4 - Variação mensal em número de exemplares e CPUE (Kg/arrasto) da ictiofauna acompanhante da pesca artesanal do camarão sete-barbas, nas áreas I (a), II (b), III (c) e média das três áreas (d).

apresentou menor média de diversidade, sendo a causadora das diferenças.

O índice de equitabilidade de Pielou (J'), também apresentou flutuações ao longo do período de estudo e padrões distintos para as áreas de coleta (Fig.5c). Na área I, a menor equitabilidade ocorreu em setembro $(0,285)$, e maior em junho (0,775) (Fig. $5 \mathrm{c})$. Enquanto que na área II, a menor foi registrada em outubro 

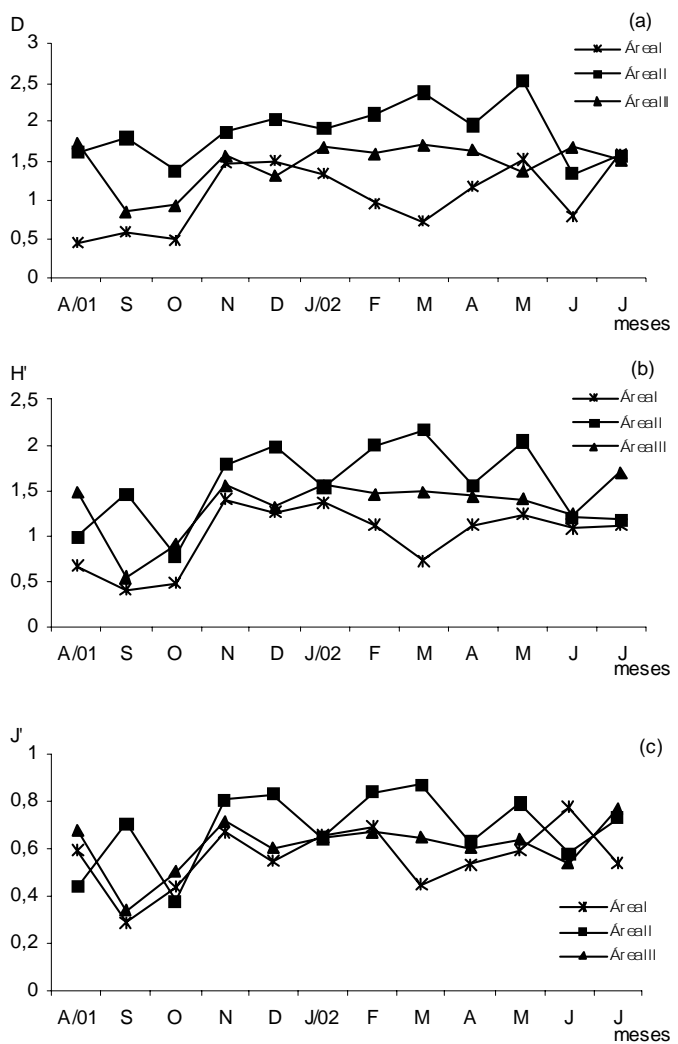

Figura 5 - Variação mensal dos índices de riqueza de espécies (D) (a), de diversidade (H') (b) e equitabilidade (J') (c), nas áreas I , II e III.

$(0,379)$ e a maior em março $(0,871)$ (Fig. 5c). $\mathrm{Na}$ área III, o mês com menor equitabilidade foi setembro $(0,341)$, e o de maior foi julho $(0,769)$ (Fig. 5 c). Não foram observadas diferenças significativas entre os índices de equitabilidade e as áreas de coleta $\left(F_{2-33}=2,511 ; p=0,096\right)$ ao longo do período de amostragem.

\section{DISCUSSÃO}

O número de espécies integrantes da ictiofauna na pesca artesanal do camarão setebarbas (Xiphopenaeus kroyeri) na região de Penha, SC, apresenta pequenas oscilações entre os anos, sendo que em 1996/97, Branco
(1999) registrou 41 espécies; no presente estudo, a ictiofauna acompanhante esteve representada por 37 espécies, pertencentes à 22 famílias. Para Branco (1999), o número de espécies da ictiofauna oscila entre as regiões, com tendência a um incremento do Sul para o Sudeste do Brasil.

Na região de Penha, SC, assim como em outras latitudes, a família Sciaenidae apresentou dominância em número e biomassa de peixes capturados, o que está de acordo com o registrado nas regiões costeiras do Sudeste/Sul do Brasil (Coelho et al., 1986; Paiva-Filho \& Schmiegelow, 1986; Giannini \& Paiva-Filho, 1990; Ruffino \& Castello, 1992/93; Santos, 1998; Branco, 1999; Krul, 1999; Hostim-Silva et al., 2002). Para Menezes \& Figueiredo (1980) essas espécies são comuns em águas rasas com fundos de areia ou lama, coincidindo com o tipo de substrato, onde atua a frota artesanal do camarão sete-barbas.

Das 37 espécies capturadas, apenas Paralonchurus brasiliensis e Stellifer spp. foram regulares nas três áreas de coleta, sendo que cerca de $75 \%$ do total das espécies foram consideradas ocasionais. Fato semelhante ocorreu no rio Itajaí-Açú, onde a maior percentagem da ictiofauna (55\%) esteve representada por espécies ocasionais (HostimSilva et al., 2002). Para Branco (1999), provavelmente a ocasionalidade das espécies pode ser atribuída a passagem/migração por esta área de pesca. Já para Saul \& Cunninghann (1995), a ausência de espécies regulares nas áreas de estudo pode estar associada à instabilidade das regiões costeiras, padrões de massas de água ou aos eventos biológicos das espécies em questão.

A ictiofauna em número de exemplares, apresentou oscilações sazonais, sendo que os picos de captura ocorreram no início do outono e final da primavera, e as menores taxas nos meses de inverno. Em relação a CPUE, foram observadas variações mensais, com registro de maiores taxa nos meses de dezembro e abril, o que é corroborado por Giannini \& Paiva-Filho (1990), na Baía de Santos e Branco (1999) na 
Armação do Itapocoroy, Penha, SC. A sazonalidade pode influenciar as taxas de captura da ictiofauna acompanhante, na pesca artesanal do camarão sete-barbas (Paiva-Filho \& Schmiegelow, 1986; Carranza-Frazer \& Grande, 1982 apud Branco, 1999). Foi encontrada diferença significativa em relação às áreas de coleta e ao número de indivíduos, indicando que na área II há menor captura, em decorrência das maiores profundidades registradas neste local.

Os valores do índice de riqueza de Margaleff (D) obtidos neste trabalho oscilaram entre as áreas, onde a área I apresentou menor média de riqueza. Para Bhukaswan (1980) apud Vieira (2000) o valor reduzido de espécies pode estar sendo provocado devido ao excesso de pesca em determinadas áreas. Para a ictiofauna da região costeira de Peruíbe, SP, Zani-Teixeira \& Paiva-Filho (1981) encontraram valores superiores de riqueza de espécie $(1,47$ e 4,85); entretanto, as características físico-químicas das áreas podem influenciar na riqueza de espécie.

O índice de diversidade de Shannon ( $\left.\mathrm{H}^{\prime}\right)$ indica o grau de complexidade da estrutura da comunidade que se estuda (Ludwig \&
Reynolds, 1988). O quadro 1 demonstra os valores de diversidades obtidos em outras regiões.

Em geral, as regiões equatoriais tendem a apresentar maior diversidade que regiões mais temperadas, o presente trabalho ressalta esse padrão onde foram obtidas as menores diversidades $(0,39$ a 2,16). Para Cecílio (1997) e Santos (2000), diversidades baixas são decorrentes de predação, falta de áreas de refúgio e alimentação para jovens.

De acordo com Ludwig \& Reynolds (1988), o índice de equitabilidade de Pielou (J') indica o grau de distribuição dos indivíduos no seu habitat, e resultados acima de 0,5 indicam uma distribuição uniforme entre as espécies. Apesar da dominância de indivíduos da família Sciaenidae, os índices de equitabilidade obtidos para a região de Penha, podem ser interpretados como uma tendência à uniformidade, se considerarmos os índices médios das áreas amostradas. Para o presente estudo, as equitabilidades variaram entre 0,28 e 0,87 . Outros trabalhos apresentam índices de equitabilidade no quadro 2.

Analisando os índices de riqueza de espécie, diversidade e equitabilidade, verificou-

Quadro 1 - Índices de diversidade (H’) obtidos em diferentes áreas de estudo.

\begin{tabular}{|c|c|c|}
\hline Local & Autor & Variação da diversidade \\
\hline Peruíbe/SP & Zani-Teixeira \& Paiva-Filho (1981) & 0,72 a 2,56 \\
\hline Baía de Santos/SP & Paiva-Filho \& Schmiegelow (1986) & 1,64 a 3,32 \\
\hline Barra da Lagoa dos Patos/RS & Pereira (1994) & 1,20 a 2,27 \\
\hline Foz do Rio São Francisco/SE-AL & Tischer \& Santos (2001) & 2,62 a 3,58 \\
\hline Tamandaré/ PE & Santos (2000) & 1,61 a 3,61 \\
\hline
\end{tabular}

Quadro 2 - Índices de equitabilidade (J') obtidos em diferentes áreas de estudo.

\begin{tabular}{|c|c|c|}
\hline Local & Autor & Variação da equitabilidade \\
\hline Barra da Lagoa dos Patos/RS & Pereira (1994) & 0,45 a 0,87 \\
\hline Tamandaré/ PE & Santos (2000) & 0,56 a 0,73 \\
\hline Foz do Rio São Francisco/SE-AL & Tischer \& Santos (2001) & 0,78 a 0,93 \\
\hline
\end{tabular}


se um padrão semelhante de variação em todas as áreas de coleta, indicando que estes índices constituem parâmetros convergentes na avaliação da organização estrutural do sistema (Castro, 1997).

\section{REFERÊNCIAS BIBLIOGRÁFICAS}

Ansari, Z.A.; Chatterfi, A.; Ingole, B.S.; Sreepada, R.A.; Rivonkar, C.U. \& A.H. Parulekar. 1995. Community structure and seazonal variation of on inshore demersal fish community at Goa, west coast of India. Estuar. coast. Shelf. Sci., 41:593-610.

Branco, J.O. 1999. Biologia do Xiphopenaeus kroyeri (Heller, 1862) (Decapoda: Penaeidae), análise da fauna acompanhante e das aves marinhas relacionadas a sua pesca, na região de Penha, SC, Brasil. Tese de Doutorado. Universidade de São Carlos, SP, $147 \mathrm{p}$.

Castro, A.C.L. 1997. Aspectos ecológicos da comunidade ictiofaunística do reservatório de barra Bonita, SP. Rev. bras. Biol., 57 (4):665-676.

Cecílio, E.B.; Agostinho, A.A.; Júlio-Júnior, H.F. \& C.S. Pavanelli. 1997. Colonização ictiofaunística do reservatório de Itaipu e áreas adjacentes. Revta. bras. Zool. 14 (1):1-14.

Coelho, J.A.P.; Puzzi, A. Graça-Lopes, R.; Rodrigues, E.S. \& O. Preto Jr. 1986. Análise da rejeição de peixes na pesca artesanal dirigida ao camarão sete-barbas (Xiphopenaeus kroyerı) no litoral do estado de São Paulo. Bolm. Inst. Pesca, São Paulo, 13 (2):51-61.

Figueiredo, J.L. \& N. Menezes. 1978. Manual de peixes marinhos do sudeste do Brasil. II. Teleostei (1). Museu de Zoologia. Universidade de São Paulo. 110 p.

Figueiredo, J.L. 1980. Manual de peixes marinhos do sudeste do Brasil. III. Teleostei (2). Museu de Zoologia. Universidade de São Paulo. 90 p.
Giannini, R. \& A. M. Paiva-Filho. 1990. Os Sciaenidae (Teleostei: Perciformes da Baía de Santos (SP), Brasil. Bolm. Inst. Oceanogr., São Paulo, 38 (1):69-86.

Hostim-Silva, M.; Vicente, M.J.D.; Figna, V. \& J.P. Andrade. 2002. Ictiofauna do rio ItajaíAçú, Santa Catarina, Brasil. Notas Técnicas da Facimar. 6:127-135.

Krul, R. 1999. Interação de aves marinhas com a pesca de camarão no litoral paranaense. Dissertação de Mestrado. Curitiba, 154 p. Ludwig, J.A. \& J.F Reynolds. 1988. Statistical ecology: a primer on methods and computing. John Wiley e Sons, INC. 338 p.

Menezes, N.A. \& J.L. Figueiredo. 1980. Manual de peixes marinhos do sudeste do Brasil: IV Teleostei (3). São Paulo: Museu de Zoologia da Universidade de São Paulo, 96 p.

Paiva-Filho, A.M. \& J.M.M. Schmiegelow, 1986. Estudo sobre a ictiofauna acompanhante da pesca do camarão sete-barbas (Xiphopenaeus kroyeri) nas proximidades da Baía de Santos - SP. I - Aspectos quantitativos. Bolm. Inst. Oceanogr., São Paulo, 34 (único):79-85.

Pereira, L.E. 1994. Variação diurna e sazonal dos peixes demersais na barra do estuário da lagoa dos Patos, RS. Atlântica, Rio Grande, 16: 5-21.

Rodrigues, E.S.; Graça-Lopes, R.; Pita, J.B. \& J.A. Coelho. 1985. Levantamento das espécies de camarão presentes no produto da pesca dirigida a camarão sete-barbas (Xiphopenaeus kroyeri Heller, 1862) no estado de São Paulo, Brasil. Bolm. Inst. Pesca, São Paulo, 12 (4): 77-85.

Ruffino, M.L. \& J.P. Castello. 1992/93. Alterações na ictiofauna acompanhante da pesca do camarão barba-ruça (Artemesia longinaris) nas imediações da Barra de Rio Grande, Rio Grande do Sul - Brasil. Nerítica, Curitiba, 7 (1-2):43-55.

Santos, M.C. F.; Freitas, A E.T.S. \& M. M. Silva. 1998. Composição da ictiofauna 
acompanhante da pesca de camarão em Tamandaré/ PE e Pontal do Peba/ AL. Bolm. Téc. Cient. CEPENE, Tamandaré, 6 (1):47-60.

Santos, M.C.F. 2000. Diversidade ecológica da ictiofauna acompanhante nas pescarias de camarões em Tamandaré (Pernambuco Brasil). Bolm. Téc. Cient. CEPENE, Tamandaré, 8 (1):165-183.

Saul, A. \& P.T.M. Cunningham. 1995. Comunidade ictiofaunística da llha do Bom Abrigo, Cananéia, São Paulo, Brasil. 2 Lanço. Arq. Biol. Tecnol. 38 (4): 1053-1069.

Sokal, R.R. \& F.J. Rohlf. 1969. Biometry, the principles and practies of statistics in biological research. W. H. Freeman and Co., San Francisco. 776 p.
Tischer, M. \& Santos, M.C.F. 2001. Algumas considerações sobre a ictiofauna acompanhante da pesca de camarões na foz do rio São Francisco (Alagoas/Sergipe - Brasil). Bolm. Téc. Cient. CEPENE, Tamandaré, 9 (1):155-165.

Vieira, I. 2000. Freqüência, constância, riqueza e similaridade da ictiofauna da bacia do rio Curuá-Uma, Amazônia. Rev. bras. Zoociências, Juiz de Fora. 2 (2): 51-76.

Zani-Teixeira, M.L. \& A.M. Paiva-Filho. 1981. Contribuição ao conhecimento da fauna íctia costeira da região de Peruíbe - SP. II. Diversidade faunística. Rev. bras. Biol., 41 (2):291-294. 